Case Report: Open Access

\title{
First Haploidentical Transplant in Peru in Pediatric Patient with Bilineal Leukemia
}

\author{
Mariela Del Carmen Moreno*, Cinthia Palacios and Yessenia Cruz
}

Hospital Nacional Edgardo Rebagliati Martins, Peru

${ }^{*}$ Corresponding author: Mariela Del Carmen Moreno, MD, PhD, Hospital Nacional Edgardo Rebagliati Martins, Av Edgardo Rebagliati, Jesús María, Peru, E-mail: moreno_mariela@yahoo.com

\begin{abstract}
Bilineal leukemia is a very rare health condition, especially in pediatric patients; it is associated with poor prognosis, even without uniformity therapeutic criteria. Hereby, we present a 4-year-old boy, who debuted as T-cell lymphoblastic lymphoma, he initially received treatment induction, which was unanswered, further studies showed evidence of being bilinear leukemia (T-AML M5). He continued the AML induction therapy followed by four consolidations, achieving CR. In the absence of HLA-matched related donor, it was decided to make haploidentical transplant of his half-brother, with individual conditioning. Seven months post HSCT, he remains in CR. This case coincides with what is reported in the literature, concerning the poor response to chemotherapy, being the stem cell transplantation the only treatment option with curative intent; and in our country due to the high costs of a transplant not related to umbilical cord, we have chosen to start the program haploidentical HSCT to offer to these patients, a possible alternative healing.
\end{abstract}

\section{Introduction}

Within the group of hybrid acute leukemias, are the biphenotypic leukemias and mixed or bilineal leukemias. Although the vast majority of acute leukemias can be classified as B, T or myeloid, a small percentage has characteristics of more than one lineage. Therefore, a final classification is not possible.

With the use of monoclonal antibodies, most acute leukemias can be classified by their phenotype, and also determine the degree of clonal promiscuity, according to the expression of myeloid and lymphoid antigenic markers [1,2].

These morphological and immunophenotypic features may be different and be present in a population of blasts (leukemia Biphenotypic) or two different blastic populations may be present in one single patient (bilineal leukemia). Leukemias that change their lineage of origin during therapy or show little differentiated features are also included in this category [3].

Leukemias of ambiguous lineage are a group of rare leukemias in children and represent less than $5 \%$ of all leukemias. The bilineal leukemias are even rarer, they represent less than 1\% [4] and probably come from a multipotent progenitor cell with the ability to differentiate atypically in both myeloid and lymphoid lineages. medical Hematologists Masters and Doctoral thesis, we have demonstrated that high and very high risk acute leukemias constitute $60 \%$ of the debut leukemias $[5,6]$, unlike what foreign literature reports [4].

There is numerical score criteria devised by EGIL (European Group for Immunologic classification of Leukemia) for immunophenotyping of biphenotypic leukemia diagnosis, however there are no well-defined quantitative standards for the diagnosis of bilineal leukemias, because they are more infrequent $[3,4]$.

For ethnic reasons our patients have difficulty finding a compatible HLA donor to opt for unrelated transplantation donor; and as mixed leukemias are a group of leukemias difficult to control with conventional strategies, our transplant center has started haploidentical transplant program, with the intention of seeking a better therapeutic option for this group.

It seems important in this particular case, because of the rarity of its presentation, the prognosis and the healing alternative recently started in our institution, since opting for an unrelated donor (umbilical cord) is very expensive for our country.

\section{Case Report}

We present the case of a 4-year-old boy with no relevant history; in August 2014 he debuted with multiple painless lymphadenopathy, initially being studied by the Department of Infectious Diseases from Edgardo Rebagliati Martins National Hospital discarding infectious etiology. In November 2014 he was readmitted by the pediatric emergency due to the persistence of lymphadenopathy associated with hepatosplenomegaly and cytopenias (thrombocytopenia and anemia) so he was hospitalized in the Pediatric Oncology Unit; where different studies were conducted:

1) Lymph node biopsy: large cell lymphoproliferative process and pleomorphic, suggestive of being double strain $\mathrm{T}($ : CD3 + / CD4 $+/ \mathrm{CD} 8)$ and B-cell (CD20 + / TdT +)

2) Bone marrow biopsy: $10 \%$ infiltration of $\mathrm{CD} 3$ + blasts marking.

3) Cytogenetics: 46XY.

4) Immunophenotype (IFT) Marrow Blood: With $11 \%$ of immature myeloid blasts

The Initial findings ( 1 and 2 ) suggested the diagnosis of 
lymphoblastic $\mathrm{T}$ cells lymphoma, so he received chemotherapy according to protocol of INDUCTION non-Hodgkin lymphoma T, for 8 weeks, in charge of the Pediatric Oncology Unit (prednisone $60 \mathrm{mg} / \mathrm{m}^{2}$ for 26 days, vincristine $1.5 \mathrm{mg} / \mathrm{m}^{2} /$ week, daunorubicin 40 $\mathrm{mg} / \mathrm{m}^{2} /$ week , Laspar $5000 \mathrm{IU} /$ day, 1 dose. methotrexate $3 \mathrm{~g} / \mathrm{m}^{2} 1$ day, Cyclophosphamide $1000 \mathrm{mg} / \mathrm{m}^{2}$ for 1 day).

During and after 8 weeks of chemotherapy the patient presented thrombocytopenia and persistent splenomegaly, because of this, pediatric hematology evaluation was requested; realizing the patient new bone marrow aspirate (BMA) and IFT, which showed $22 \%$ blasts $\mathrm{CD} 34+/ \mathrm{CD} 117+/ \mathrm{CD} 7+/ \mathrm{CD} 13+/ \mathrm{CD} 33+/ \mathrm{CD} 11 \mathrm{~b}+/ \mathrm{CD} 22+/$ CD $71+/ C D$ 64+/HLA-DR+/CD 3/CD 4-/CD 8-/16-CD/CD 10-/CD 203-/15-CD/CD 36-/99-CD/CD 5-/CD 2/NG2-/IREM2-/TCRgd-/ TCRab--: compatible results with Acute Myeloid Leukemia (AML) monocytic, the patient was transferred to the service of Pediatric hematology and received chemotherapy as bilineal acute leukemia.

On admission to our service, molecular study (E2A/PBX1, MLL/ AF4, BCR/ABLp190, BCR/ABLp210, TEL/ AML1, AML1-ETO, FLT3-ITD and JAK2 V617F) was performed: all came up negative. $\mathrm{He}$ later received induction according to protocol LMA; with persistence post this chemotherapy; therefore a second high-dose cytarabine induction was decided, achieving complete morphological remission (CR) by BMA and IFT. He continued with consolidation schemes: 4 courses of high-dose cytarabine in combination with other chemotherapeutic agents, remaining in complete remission morphologically and by IFT. The patient received intrathecal triple prophylactic therapy to prevent infiltration to the nervous central system.

In the context of a very high risk leukemia and not having a HLAcompatible related donor, it was decided to execute the haploidentical transplant of the patient's 18-year-old half-brother, he received as individualized conditioning: fludarabine $30 \mathrm{mg} / \mathrm{m}^{2} / \mathrm{d}$ for 5 days and busulfan $4 \mathrm{mg} / \mathrm{kg} / \mathrm{d}$ for 3 days; Infusion of Stem Cells; Peripheral blood source (11/02/15): $6.7 \times 10^{6} \mathrm{CD} 34 / \mathrm{kg},\left(11.45 \times 10^{6} \mathrm{CD} 34 /\right.$ $\mathrm{kg}$ was cryopreserved ). On day +2 he presented febrile neutropenia unfocused with negative cultures and received broad-spectrum antibiotic therapy.

On day +16 marrow engraftment was evident. Prophylaxis for graft versus host disease was post Cyclophosphamide $(50 \mathrm{mg} / \mathrm{kg} / \mathrm{d})$ for two days + MMF to $15 \mathrm{mg} / \mathrm{kg} / \mathrm{d}$ for 30 days and tacrolimus $0.5 \mathrm{mg}$ every 12 hours being regulated by serum level for 6 months.

He was discharged on day +19 post transplant in good clinical conditions. He reentered the day +25 , because of fever without focus, associated with dermal rash pruritic morbilliform positive for CMV viral load was found by PCR; so he was treated with intravenous ganciclovir for 14 days. Then he was discharged for outpatient monitoring, in good clinical conditions so far.

\section{Discussion}

The distinction between Biphenotypic and bilinear leukemia is not well established in the literature $[7,8]$. In most reports, cases of leukemia are combined with bilineal Biphenotypic. Despite the best recognition by the sophisticated methods of immunophenotypic analysis, the treatment decision is still controversial, due to lack of criteria uniformity, the limited cases data and poor prognosis.

Johns Hopkins Medical Institution published a series of 16 cases of patients with bilineal leukemia among children and adults, of which nine are T-myeloid and seven B myeloid. Only six of these 16 cases achieved complete remission after the induction chemotherapy; and three of them underwent stem cell transplantation; finally two of relapsed and died, the third remains free of disease 2.5 years after diagnosis, and the remaining three, relapsed and died. Four patients $\mathrm{B}$ myeloid and T-myeloid six failed the induction chemotherapy. Of the 10 patients who failed induction, three died within 10 days after diagnosis. Seven were undergoing transplantation, of which six relapsed soon after, the rest remains in remission 4.5 years after diagnosis [4].
The Data presented in the literature suggests that the bilineal leukemia has a very bleak prognosis, for both children and adults; related to the underlying chromosomal abnormalities. A low rate of complete post induction and remission short survival times have been reported despite very ablative chemotherapy and hematopoietic stem cell transplantation $[9,10]$.

In our institution, such leukemias are handled with schemes resulting from the combination of the two lines of treatment.

Our patient debuted as lymphoma leukemia $\mathrm{T}$ by lymph node biopsy and BM biopsy but presented an IFT with myeloid blast about $20 \%$. However, due to the lack of criteria uniformity for the definition of bilineal leukemia, the delay in processing samples and lack of the full range of monoclonal markers in the institution it was initially treated as non-Hodgkin lymphoma; and subsequently, as acute leukemia.

Although this type of leukemia is frequently associated with chromosomal abnormalities, our patient had normal karyotype and negative molecular tests; they are still favorable prognostic indicators. At the time of publication the patient remains in complete remission after transplant.

The Hematopoietic stem cell transplantation (HSCT) seems to be one of the most effective options when handling this type of very aggressive leukemias. The possibility to start a program transplant not related to umbilical cord in our country is very unlikely due to economic reasons; this has prompted us to start the haploidentical program HSCT to offer these patients, a possible curative alternative to poor responses to conventional therapy.

\section{References}

1. Matutes E, Pickl WF, Van't Veer M, Morilla R, Swansbury J, et al. (2011) Mixed-phenotype acute leukemia: clinical and laboratory features and outcome in 100 patients defined according to the WHO 2008 classification. Blood 117: 3163-3171.

2. Steensma DP (2011) Oddballs: acute leukemias of mixed phenotype and ambiguous origin. Hematol Oncol Clin North Am 25: 1235-1253.

3. Porwit A, Béné MC (2015) Acute leukemias of ambiguous origin. Am J Clin Pathol 144: 361-376

4. Rubnitz JE, Onciu M, Pounds S, Shurtleff S, Cao X, et al. (2009) Acute mixed lineage leukemia in children: the experience of St Jude Children's Research Hospital. Blood 113: 5083-5089.

5. Moreno LM (2010) Características clínicas, epidemiológicas, sobrevida libre y sobrevida total en pacientes pediátricos con Leucemia Linfática Aguda: Experiencia del Hospital Rebagliati 2000-2005. Lima, Peru.

6. Murillo VS (2011) Características clínicas, epidemiológicas, sobrevida libre y sobrevida total en pacientes pediátricos con Leucemia Mieloide Aguda: Experiencia del Hospital Rebagliati 2000-2005 Lima, Perú.

7. Vizcaino M, Guzman C, De los reyes I, Quijano S, Campos A (2010) Diagnóstico de leucemias bifenotípicas por citometría de flujo. Biomedica 30: 22-26.

8. Weir EG, Ali Ansari-Lari M, Batista DA, Griffin CA, Fuller S, et al. (2007) Acute bilineal leukemia: a rare disease with poor outcome. Leukemia 21 : 2264-2270.

9. Oliveira JL, Kumar R, Khan SP, Law ME, Erickson-Johnson M, et al. (2011) Successful treatment of a child with T/myeloid acute bilineal leukemia associated with TLX3/BCL11B fusion and 9q deletion. Pediatr Blood Cancer 56: 467-469.

10. Gerr H, Zimmermann M, Schrappe M, Dworzak M, Ludwig WD, et al. (2010) Acute leukaemias of ambiguous lineage in children: characterization, prognosis and therapy recommendations. Br J Haematol 149: 84-92. 